\title{
Use of Entropy in the Assessment of Uncertainty of River Runoff Regime in Poland
}

\author{
Dariusz WRZESIŃSKI \\ Adam Mickiewicz University, Department of Hydrology and Water Management, \\ Poznań, Poland; e-mail: darwrze@amu.edu.pl
}

\begin{abstract}
The objective of this paper is to describe spatial differences in the uncertainty of features of the runoff regimes of Polish rivers based on entropy in Shannon's information theory. They included: the entropy of monthly river runoff and the entropy of river runoff distribution over time. An analysis of monthly flow series for the years 1951-2010 from 395 gauging stations located on 248 rivers in Poland was performed. This allowed a quantitative determination of the degree of uncertainty of two regime characteristics indirectly establishing the predictability, regularity, and stability of their appearance and their spatial variability. An analysis of relations between the calculated entropy, as well as between the entropy and the classical parameters commonly used was performed in describing the hydrological regime. The obtained grouping of rivers into four categories in terms of entropy of volume and distribution of runoff in the annual cycle clearly coincides with the types of river regime distinguished in Poland.
\end{abstract}

Key words: Shannon's theory, typology, hydrology, East-Central Europe.

\section{INTRODUCTION}

The effect of climate changes and variations and human activity on the conditions of river runoff has been generally broadly recognised and docu-

Ownership: Institute of Geophysics, Polish Academy of Sciences;

(C) 2016 Wrzesiński. This is an open access article distributed under the Creative Commons

Attribution-NonCommercial-NoDerivs license,

http://creativecommons.org/licenses/by-nc-nd/3.0/. 
mented. An objective analysis of links between climatic and hydrological factors requires the availability of studies illustrating the observed relations in quantitative terms (Hattermann et al. 2013, Kundzewicz and Huang 2010). It is important to understand both the multi-annual and seasonal dynamics of river runoff due to contemporary changes in water cycle. Measures of the stability and uncertainty of the runoff regime are helpful in this matter (Wrzesiński 2010, 2013a,b), because a significant socio-economic problem involves not only the magnitude of water resources, but also their accessibility, permanence, and predictability. In this context, runoff regime can be treated as an interesting tool helpful in detecting spatial and temporal changes in the volume and seasonality of runoff, and in establishing present and future surpluses and deficits of water. Therefore, the research on the hydrological regime deals with different aspects of runoff conditions in an annual cycle, including extreme phenomena, for example floods (Strupczewski et al. 2016).

Uncertainty is a feature inherent in the natural environment. While accepting its existence, we should strive to determine its degree. This can contribute to a better understanding of processes occurring in nature, and improve their modelling. Therefore, the goal of the cognitive process is not to eliminate uncertainty, but to show how to combine deterministic modelling methods with uncertainty estimation in order to improve the quality of models and forecasts.

Entropy as a measure of the degree of uncertainty finds application in many fields of science, including hydrology (Singh 1997). Here it is usually employed as a measure of the uncertainty of, e.g., hydrological simulation models (Amorocho and Espildora 1973, Chapman 1986), or the occurrence and distribution of precipitation over time (Maruyama and Kawachi 1998). Krasovskaia $(1995,1997)$ used entropy to establish a typology of river runoff regimes, and Barberis et al. (2003) to assess regime stability as a measure of the hydrological similarity of catchments. As a measure of expected information, entropy has been employed, e.g., in research on the precipitationrunoff relation (Krstanovic and Singh 1992). The maximum entropy principle finds application, e.g., in an analysis of the frequency of hydrological variables (Sonuga 1972, 1976; Dalezios and Tyraskis 1989, Koutsoyiannis 2005). An interesting method of assessing the accessibility of potential water resources at a variety of regional scales based on atmospheric precipitation was proposed by Kawachi et al. (2001) and Maruyama et al. (2005). The authors applied two entropy measures to calculate the entropy of precipitation: the entropy of the intensity of precipitation (intensity entropy, IE), and the entropy of the distribution of precipitation in time (apportionment entropy, AE). Barberis et al. (2003) studied possible application of entropy in constructing an index for the classification of river regimes based on the 
monthly discharge coefficient (the Pardé coefficient). Those methodological proposals find application in assessing the uncertainty of features of the runoff regimes of rivers in Europe and Poland (Wrzesiński 2013a, b, 2014).

The aim of the paper is to present spatial differences in the uncertainty features of the runoff regime of rivers in Poland based on entropy measures derived from Shannon's (1948) information theory. The research tasks include establishing links between the analysed uncertainty measures and other hydrological characteristics (river runoff variability, volume of groundwater flow), and examining their application in runoff regime characterization.

\section{STUDY AREA AND MATERIALS}

Because of the spatial aspect of the analysis, the scope of the research and employed statistical approaches required a numerous objects with the data series as long as possible. Because the analysis focused on measures of the uncertainty of runoff regime features affected not only by natural changes and variations in climatic conditions, but also by human activity, the entire available hydrometric material from the years 1951-2010 was used, irrespective of its statistical and genetic homogeneity. It included monthly river runoff of 395 gauging stations on 248 rivers (Fig. 1). The hydrometric data were obtained from the Institute of Meteorology and Water Management - PIB.

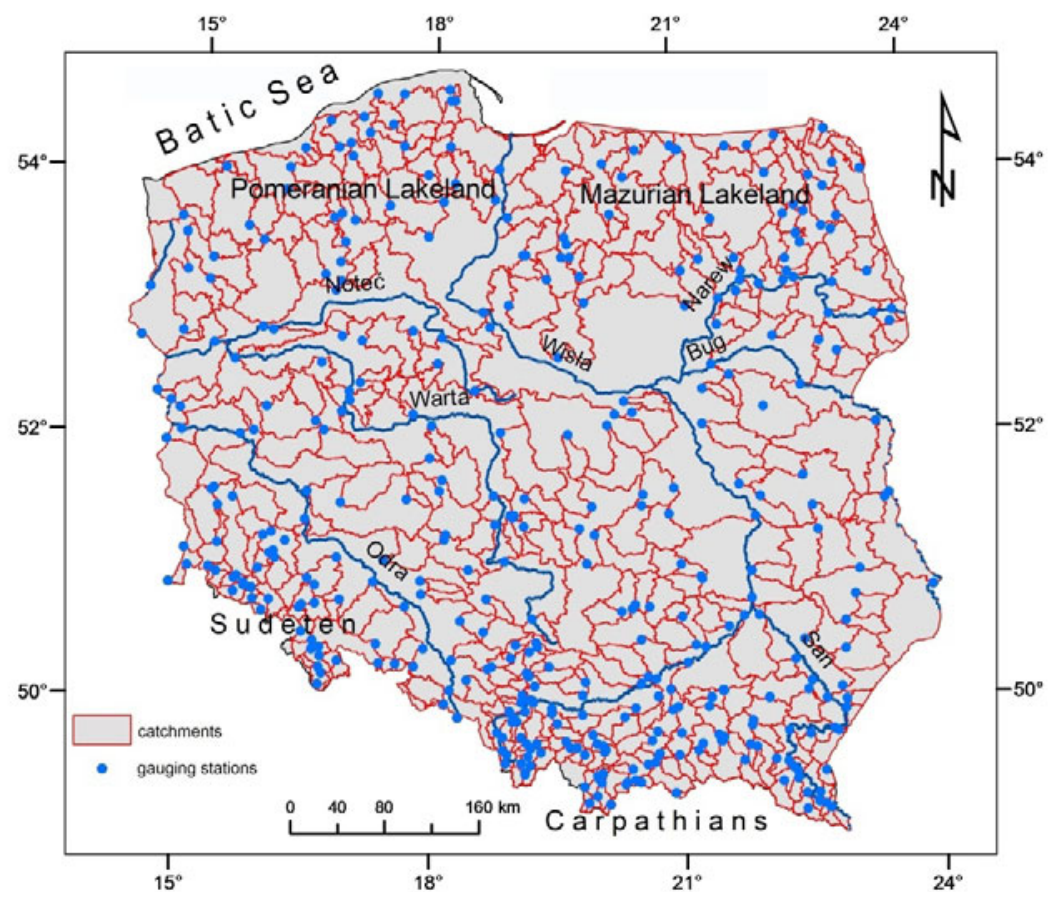

Fig. 1. Location of the gauging stations and catchments. 


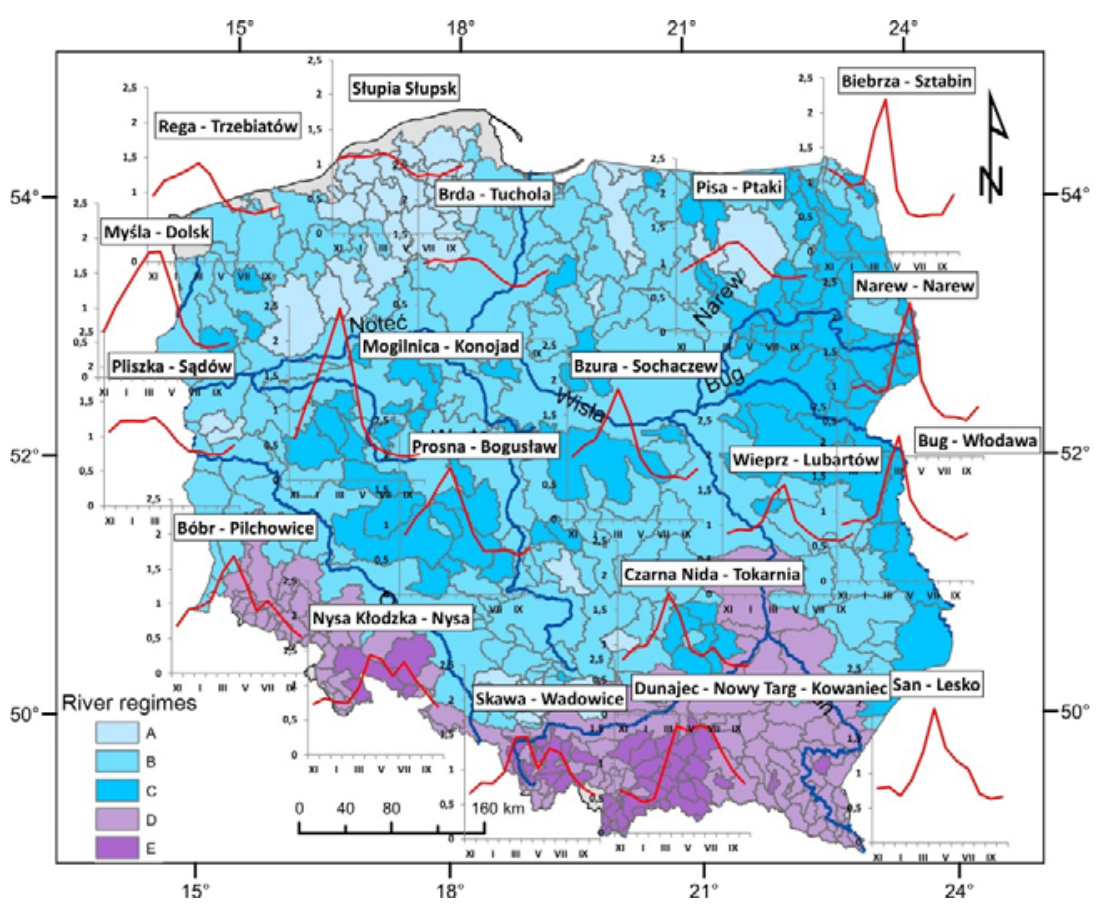

Fig. 2. River runoff regimes in Poland (after Wrzesiński 2013a). A - nival, poorly developed; B - nival, moderately well developed; $\mathrm{C}$ - nival, very well developed; D - nival-pluvial; E - pluvio-nival.

The analysis embraced rivers of Poland, an area characterised by relatively high differences, even at the regional scale, in environmental conditions, both climatic, as demonstrated by Woś (2010) with his 28 climatic regions distinguished here, and hydrological, manifested in a variety of supply conditions and patterns of river runoff seasonality. As a result, five types of river regimes occur here. The main or major criteria were the kind of supply and the runoff distribution in the annual cycle, as expressed by the pattern and values of the monthly discharge coefficient $(k)$ (Dynowska and Pociask-Karteczka 1999). The monthly discharge coefficient $\left(k_{i}\right)$ of the $i$-th month was calculated as the ratio of the multi-annual monthly discharge and multi-annual yearly discharge. This was the criterion employed when determining the types of regime of the studied rivers (Fig. 2).

Type A: nival regime, poorly developed. It is characteristic of rivers with the mean discharge in spring months not exceeding $130 \%$ of the mean annual discharge. It largely concerns rivers of the eastern part of the coastal region and the Pomeranian Lakeland. This is also the type of regime of some rivers in the Mazurian Lakeland (e.g., the Pisa River), and on the Silesian- 
Cracow Upland. Low variability of river runoff is typical of these rivers. In the case of coastal and lakeland rivers, this is largely due to a high retaining capacity of their basins, as well as a high lake percentage and a great number of closed basins. Upland rivers owe their steady runoff patterns to a rich groundwater aquifer of carbonate rocks, high fissure density, and high karstification, and those in industrial areas, to human interference in the water cycle.

Type B: nival regime, moderately well developed. It is represented by rivers with the mean discharge in spring months varying from 130 to $180 \%$ of the mean annual discharge. They are located in the north of the country, e.g., in the western part of the coastal region (e.g., the Rega River), western part of the Mazurian Lakeland, in the central part - transit rivers, e.g., the Vistula, Oder, and Warta River with the Noteć River, and in the upland belt - rivers of the Warta and Vistula interfluve.

Type C: nival regime, very well developed. It is represented by rivers with the mean discharge in spring months higher than $180 \%$ of the mean annual discharge. They show the highest variability in monthly runoff in the annual cycle. They occur in the lowland part of Poland, from the Myśla River in the west, through the Prosna River basin and the Bzura River basin in the central part of the country, to the majority of rivers in the east of the country in the Narew and Bug basins. High meltwater floods occur on those rivers in spring, followed by a rapid recession of river runoff, and transition to a period of the low summer-autumn flow.

Type D: nival-pluvial regime. It is characteristic of rivers with the mean discharge in spring months usually amounting to $130-180 \%$ of the mean annual discharge. They show a marked increase in discharge in the summer months, amounting to at least $100 \%$ of the mean annual discharge. This type is represented by all Sudeten and the majority of Carpathian rivers as well as the transit Vistula River in its upper course; its regime along this section is determined by its Carpathian tributaries.

Type E: pluvio-nival regime. This type embraces rivers with the mean discharge in summer months higher or almost equal to the mean discharge in spring, in both cases usually amounting to $130-180 \%$ of the mean annual discharge. In the Sudetes, such regularity is represented by the Nysa Kłodzka River, and in the Carpathians, by the upper Vistula River, e.g., the Soła, Skawa River, and rivers in the Dunajec River basin.

\section{METHODS}

As one of the measures of the uncertainty of a random variable, entropy can be calculated using Shannon's (1948) information theory. According to the theory, the uncertainty of a variable, or the uncertainty of its probability distribution, is the negative expected value of the logarithm of its distribution 
density function. Entropy assumes a maximum value when the probabilities are the same, and approaches zero when some value of the variable has a probability of one.

It was possible to solve the research problem with the application of methods of measuring runoff regime uncertainty adopted by the author in his works (Wrzesiński 2013a, b, 2014). In the research, entropy theory was employed to analyse series of monthly runoff. In order to determine the uncertainty of runoff regime characteristics in quantitative terms, the entropy of the runoff volume, and the entropy of the runoff distribution in the annual cycle was used.

Runoff volume entropy was calculated in the following stages:

a accumulation of a data set - monthly river runoff from the analysed multiannual with a population size of $N=12 \times m$ ( $m$-number of years),

a division of the data set into $n$ equal class intervals,

口 calculation of size $f_{i}$ of each class $i$ to make a table of size distribution $\left\{f_{i}\right\}$,

a estimation of probability $p_{i}=f_{i} / N$ for the entire range of data in each class $i$, and

- calculation of entropy $E_{H}$ from the formula:

$$
E_{H}=-\sum_{i=1}^{n}\left(\frac{f_{i}}{N}\right) \log _{2}\left(\frac{f_{i}}{N}\right) .
$$

where $n$ is the number of classes and $f_{i}$ is the size of class $i$.

So defined, the entropy of runoff volume $\left(E_{H}\right)$ assumes values from the interval $0 \leq E_{H}<\infty$, and can be treated as a measure of the uncertainty of monthly runoff.

The entropy of runoff distribution over time was defined assuming $r_{i}$ to be the monthly river runoff in the $i$-th month of the year. The annual runoff $R$, therefore, can be expressed as the sum of $r_{i}$, starting from $i=1$ to 12 . In this case, probability $p_{i}$ can be calculated as the $r_{i} / R$ ratio. By employing information entropy, we obtain a measure of disorder in the distribution of monthly runoff over the year $\left(E_{D}\right)$. This can be expressed as follows:

$$
E_{D}=-\sum_{i=1}^{12}\left(r_{i} / R\right) \log _{2}\left(r_{i} / R\right) .
$$

The values of runoff distribution entropy are contained in the interval from 0 to $\log _{2} 12$, with the maximum $\left(E_{D}=\log _{2} 12=3.58\right.$ bits $)$ obtained when the annual runoff is distributed evenly over all months of the year $\left(p_{1}=p_{2}=\right.$ $\left.p_{3}=\ldots p_{n}=1 / n\right)$. When the entire annual runoff occurs in a single month, the entropy assumes its minimum value $\left(E_{D}=0\right)$. 
In the mathematical-statistical processing of source data, procedures offered by Microsoft's Excel program were used. The graphic form was prepared with the application of programs ArcGIS 10.1 [ESRI] and CorelDRAW 12 [Corel].

\section{RESULTS}

\subsection{Entropy of runoff volume}

The uncertainty of monthly river runoff in the analysed gauging stations is expressed by the entropy of runoff volume $\left(E_{H}\right)$. It varies from 0.532 to 3.599 bits. Low values, often under 1.0 bit, indicative of high certainty of monthly river runoff, are observed on most lakeland rivers and on lowland rivers in the Oder and Vistula basins (Fig. 3A). The highest entropy of monthly runoff, exceeding 2.5 bits, i.e., the highest uncertainty of their volume, characterises mountain rivers.

The regional distribution of the entropy of monthly runoff is to a certain degree similar to the map of annual runoff (Fig. 3B). Rivers with low entropy of monthly runoff usually also show low annual runoff values, and vice versa: the least predictable monthly runoff are observed in the case of mountain rivers characterised by the highest annual runoff values. The research revealed a strong dependence of monthly runoff entropy on annual runoff volume, expressed by the calculated correlation coefficient $r=0.889$ ( $p<$ $0.001)$.

Other regime features also affect the uncertainty of monthly runoff, e.g., their variability and contribution of groundwater flow in total runoff. High runoff variability of monthly runoff series causes less certain and less predictable their volume. The observed dependence of the entropy of monthly runoff on the variability of daily flows is expressed by the calculated correla-
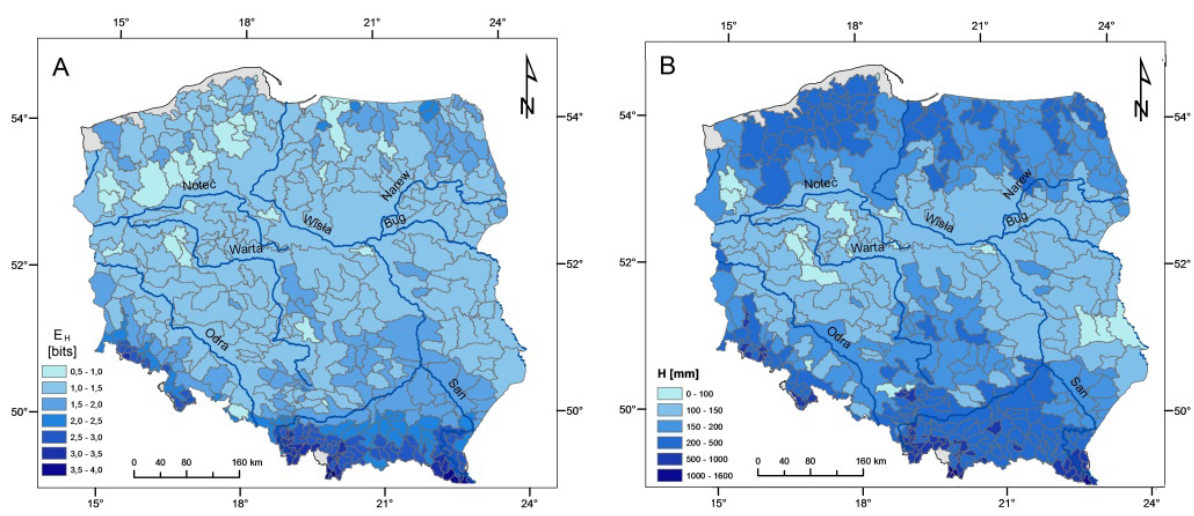

Fig. 3. Entropy of monthly runoff (A) and average runoff values (B). 

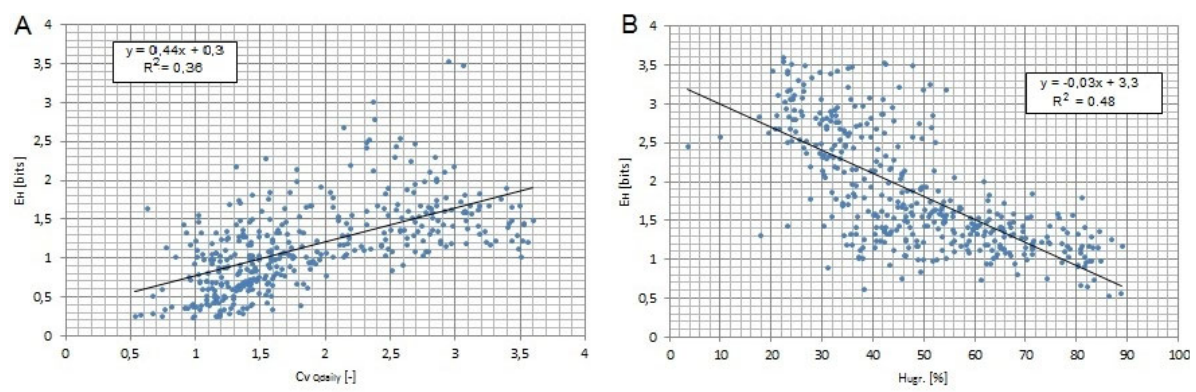

Fig. 4. Relationship between the entropy of monthly runoff and: A - coefficient of variation of daily flows, $\mathrm{B}$ - contribution of groundwater flow in total runoff.

tion coefficient $r=0.597(p<0.001)$ (Fig. 4A). A different dependence, although even more statistically significant $(r=-0.689, p<0.001)$, is observed between runoff entropy and the contribution of groundwater flow in total river runoff (Fig. 4B). Its high share is indicative of a large storage capacity of a catchment. This makes runoff values more uniform, and in consequence leads to lower entropy of runoff volume, and therefore to higher certainty of the obtained runoff volume.

\subsection{Entropy of runoff distribution in the annual cycle}

The entropy of distribution of monthly runoff over a year shows values from 0 to $\log _{2} 12=3.58$ bits. This type of entropy is expressed in per cent values, with a maximum of 3.58 assumed to constitute $100 \%$. The entropy of distribution of monthly runoff over a year varies from 78.5 to $99.6 \%$. The monthly values are relatively uniform, for example in comparison to other European rivers (Wrzesiński 2010, 2013b). In spatial terms, however, this type of entropy clearly sets apart mountain rivers and those showing a welldeveloped nival regime typical for rivers in the central and eastern parts of the country: they have the lowest values of entropy of distribution of monthly runoff (Fig. 5). Exceptions in the central part are large transit rivers: the Vistula and the Warta Rivers, with high values of runoff distribution entropy. Low entropy of distribution of monthly runoff over a year suggests non-uniform distribution over time involving a high concentration of runoff in a short period of the year. With an increase in entropy, runoff becomes more equalised in the annual cycle. The group of rivers with an average distribution entropy includes those with well-developed nival regime, and those with combined regime: pluvial-nival and nival-pluvial, e.g., the Soła or Dunajec Rivers. In both cases, however, the period of higher runoff is similar and longer than in the case of rivers with the lowest entropy, hence they show higher entropy of runoff distribution. Apart from the great rivers (the 


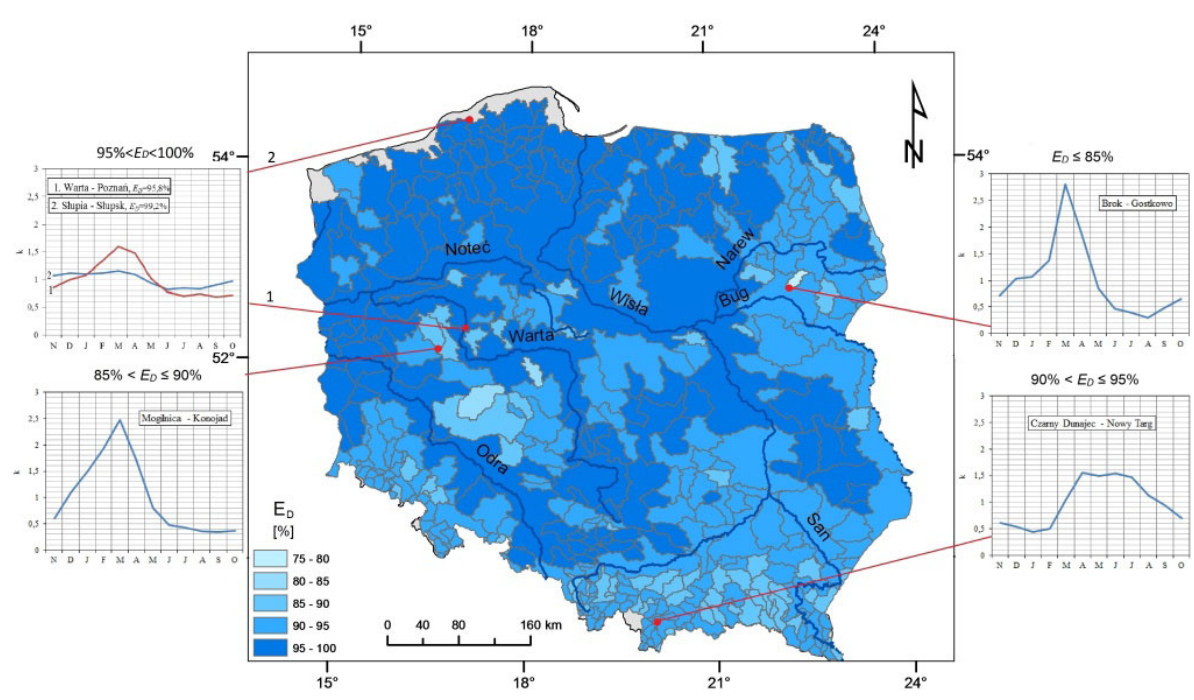

Fig. 5. Entropy of monthly runoff distribution in the annual cycle and monthly discharge coefficients $(k)$ of selected rivers with different entropy values.
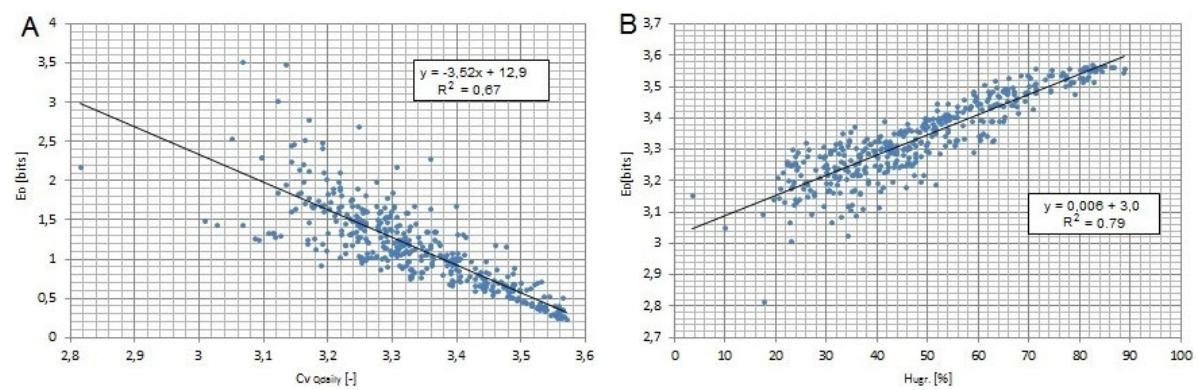

Fig. 6. Relationship between the entropy of distribution of monthly runoff in a year and: A - coefficient of variability of daily discharges, and B - contribution of groundwater flow in total runoff.

Vistula, Oder, Warta Rivers), the highest entropy $\left(E_{D}>95 \%\right)$ and the most uniform runoff values during the year are recorded for the majority of lakeland rivers, those in the upper course of the Warta River basin, in the lower course of the Oder and Vistula River basins. Extremely high entropy values $\left(E_{D}>99 \%\right)$ are characteristic of rivers with natural, poorly developed nival regimes (coastal and lakeland rivers), as well as those with runoff features impacted by human activity.

The dependence of the entropy of monthly runoff distribution in time on the volume of annual runoff is not as strong as in the case of the entropy of monthly runoff. A considerably stronger statistical correlation is observed 
between the entropy of runoff distribution over a year on the one hand, and the coefficient of variation of daily discharges and contribution of groundwater flow in total runoff on the other (Fig. 6). Rivers characterised by highly variable runoff tend to show low entropy of runoff distribution, i.e., stronger concentration of runoff over a year. Those with a high contribution of groundwater flow and low variability of discharges show higher entropy of runoff distribution, as manifested by its more uniform distribution in the annual cycle (Wrzesiński 2013a).

\subsection{Relations between the entropy of runoff volume and the entropy of runoff distribution over a year}

The values of entropy $E_{H}$ and $E_{D}$ calculated for each river are sets of data with various stochastic properties. They were unified so that their mean values equalled zero and standard deviations to 1 . The data standardisation was conducted according to the formula:

$$
x^{\prime}=\frac{x-\bar{x}}{S},
$$

where $x^{\prime}$ is the standardised value of entropy $\left(E_{H}\right.$ or $\left.E_{D}\right), x$ is the value of entropy $E_{H}$ or $E_{D}$, and $\bar{x}$ and $S$ are the mean and standard deviation, for the set of entropy $E_{H}$ or $E_{D}$, respectively.

The pairs of standardised entropy values of monthly runoff and their distribution in time for all rivers are presented in a scatter diagram (Fig. 7A). It permits to asses relations between the entropy, and to detect possible patterns in their spatial differences. The axes of the diagram constructed based on the standardised entropy are lines of their mean values. They can be regarded as lines dividing the entropy into various kinds of relations, and can be used to perform a very simple grouping. Therefore, the mean values of the two entropies provided the basis for the grouping of the analysed rivers into four categories. The basic statistics differentiating the distinguished categories are presented in Table 1.

The spatial distribution of particular categories of rivers distinguished using the entropy criterion of runoff volume and its distribution over time presents a fairly simple image in the case of the two extreme categories (Fig. 7B). Category B includes rivers with high entropy of volume and distribution of monthly runoff in time. They show high uncertainty (low predictability) of the volume of monthly runoff, but also their uniform distribution in time. This category is the least numerous one: it accounts for $7.3 \%$ of all of the analysed profiles. They concern rivers with the highest runoff entropy with the mean values amounting to $E_{H}=2.42$ bits and $E_{D}=$ $94.2 \%$ (Table 1). This holds for the upper Vistula River and for some moun- 
A

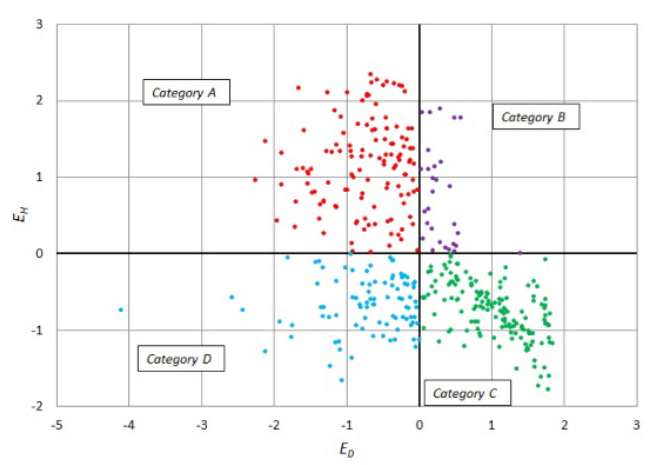

B

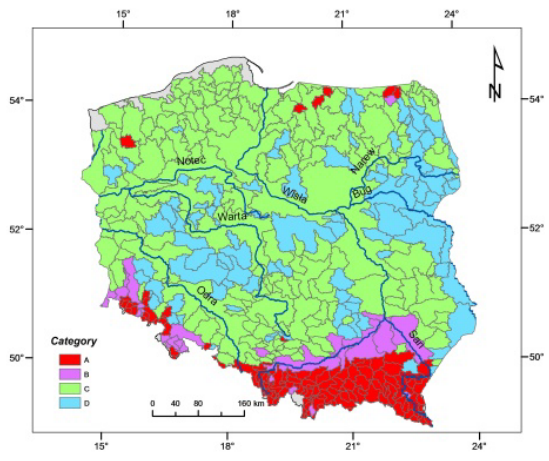

Fig. 7. Relations between entropy of runoff volume and distribution of monthly runoff in time (standardised values) (A) and spatial distribution of river basins in the particular categories (B).

Table 1

Statistical parameters of categories of rivers distinguished on the base of entropy of runoff $\left(E_{H}\right)$ and distribution of monthly runoff over time $\left(E_{D}\right)$

\begin{tabular}{|c|c|c|c|c|c|}
\hline \multicolumn{2}{|c|}{ Statistics } & Category A & Category B & Category C & Category D \\
\hline \multirow{3}{*}{ Mean } & $E_{H}[\mathrm{bit}]$ & 2.72 & 2.42 & 1.31 & 1.36 \\
& $E_{D}[\%]$ & 90.4 & 94.2 & 96.7 & 90.5 \\
& $H[\mathrm{~mm}]$ & 497 & 471 & 206 & 136 \\
\hline \multirow{4}{*}{ Max. } & $E_{H}[\mathrm{bit}]$ & 3.60 & 3.27 & 1.84 & 1.85 \\
& $E_{D}[\%]$ & 93.0 & 98.0 & 99.6 & 93.1 \\
& $H[\mathrm{~mm}]$ & 1592 & 848 & 578 & 201 \\
\hline \multirow{3}{*}{ Min. } & $E_{H}[\mathrm{bit}]$ & 1.87 & 1.86 & 0.53 & 0.62 \\
& $E_{D}[\%]$ & 85.1 & 93.2 & 93.3 & 78.5 \\
\hline \multirow{2}{*}{ Standard } & $H[\mathrm{~mm}]$ & 205 & 246 & 96 & 59 \\
deviation & $E_{H}[\mathrm{bit}]$ & 0.44 & 0.48 & 0.27 & 0.27 \\
$S$ & $E_{D}[\%]$ & 1.84 & 0.95 & 1.79 & 2.39 \\
\hline \multirow{2}{*}{ Variation } & $H[\mathrm{~mm}]$ & 240 & 190 & 77 & 33 \\
coefficient & $E_{H}$ & 0.162 & 0.198 & 0.207 & 0.196 \\
$C v$ & $E_{D}$ & 0.020 & 0.010 & 0.019 & 0.026 \\
\hline$N$ & $H$ & 0.483 & 0.403 & 0.375 & 0.240 \\
\hline
\end{tabular}


tain rivers. Their monthly runoff are the most uncertain, but they are relatively evenly distributed in time. They can be regarded as rivers with the least predictable runoff, both in terms of volume and distribution in time.

Category D is more numerous (22.8\% of gauging stations). Here rivers show the lowest entropy of both monthly runoff and runoff distribution over the year. The mean values equal $E_{H}=1.36$ bits and $E_{D}=90.5 \%$ (Table 1 ). This means that they are distinguished by high predictability of volume of their monthly runoff, and strong runoff concentration over a year. This category includes rivers with very well developed nival regime, located in the central and eastern parts of the country, with the exception of the transit rivers.

The two remaining categories, $\mathrm{A}$ and $\mathrm{C}$, are transitional between those described above. This is determined by their basic statistics (Table 1) as well as their geographical location (Fig. 7B). This is particularly evident in the case of category $\mathrm{C}$, including the largest proportion (37.7\%) of the analysed stations. It especially concerns lakeland rivers, transit rivers - the middle and lower Vistula River, the Oder and Warta Rivers almost along their entire lengths, and rivers located in the upper part of the Warta River basin and the central part of the Vistula River basin. Rivers of this category are characterised by a high level of certainty and predictability of the volume of their monthly runoff, but also by uniform runoff distribution over a year.

Their opposites, rivers with low predictability of monthly runoff volume but with high runoff concentration over a year, belong to category A, accounting for $32.2 \%$ of the analysed stations. It particularly includes mountain rivers: the majority of Carpathian ones, and those in the Sudetes. Single rivers also occur in the north of the country - Fig. 7B.

\section{DISCUSSION AND CONCLUSIONS}

The proposed uncertainty measures derived from Shannon's (1948) information theory can readily be used to characterise not only pluvial regime (Kawachi et al. 2001, Maruyama et al. 2005), but also river runoff regime. This has been observed when analysing regimes of European rivers (Krasovskaia 1995, 1997; Barberis et al. 2003, Wrzesiński 2013b). The obtained grouping of rivers into four categories in terms of the entropy of volume and distribution of runoff in the annual cycle clearly coincides with the types of river regime distinguished in Poland (Dynowska and PociaskKarteczka 1999). The measures of runoff regime uncertainty employed in this paper enrich the knowledge on patterns in the spatial distribution of river runoff in Poland and can be an interesting tool in a study of a regime, and a basis for its characterisation. The performed analysis shows that the measures also permit detecting and assessment of the scale of transformation of 
runoff regime features resulting from human activity, or changes and variations in climatic conditions.

Using Shannon's information theory, two measures were proposed to assess the uncertainty of runoff regime features of rivers in Poland: the entropy of volume of monthly runoff and the entropy of distribution of monthly runoff in the annual cycle. This methodology made it possible to establish indirectly the predictability, regularity, and stability of appearance of the analysed variables.

Spatial differences in the entropy of runoff volume, especially in the case of rivers with the highest values of this measure, are clearly related to the distribution of this runoff index: rivers with low entropy of monthly runoff have usually low annual runoff values. The least predictable volumes of monthly runoff are observed in case of mountain rivers with the highest annual runoff values. The uncertainty of volume of monthly runoff is also affected by other regime features: runoff variations and contribution of groundwater flow in the total value.

Spatial differences in the entropy of distribution of monthly runoff clearly set apart mountain rivers and those with a well-developed nival regime situated in the central and eastern parts of the country: they have the lowest entropy values. The most uniform runoff values over a year as manifested by high entropy values characteristic of large rivers (the Vistula, Oder, and Warta Rivers) and the majority of lakeland rivers. Extremely high entropy values $\left(E_{D}>99 \%\right)$ are typical of rivers with natural, poorly developed nival regime (coastal and lakeland rivers), as well as those with runoff characteristics influenced by human activity. The analysis shows that rivers with high runoff variability also show low entropy of its distribution, and therefore higher runoff concentration in the annual cycle. Those with a high contribution of groundwater flow and lower runoff variability show higher runoff distribution entropy, more uniform in the annual cycle.

\section{References}

Amorocho, J., and B. Espildora (1973), Entropy in the assessment of uncertainty in hydrologic systems and models, Water Resour. Res. 9, 6, 1511-1522, DOI: 10.1029/WR009i006p01511.

Barberis, C., P. Molnar, P. Claps, and P. Burlando (2003), Hydrologic similarity of river basins through regime stability, Dipartimento Di Idraulica, Trasporti ed Infrastrutture Civili, Politecnico Di Torino. 
Chapman, T.G. (1986), Entropy as a measure of hydrologic data uncertainty and model performance, J. Hydrol. 85, 1-2, 111-126, DOI: 10.1016/00221694(86)90079-X.

Dalezios, N.R., and P.A. Tyraskis (1989), Maximum entropy spectra for regional precipitation analysis and forecasting, J. Hydrol. 109, 1-2, 25-42, DOI: 10.1016/0022-1694(89)90004-8.

Dynowska, I., and J. Pociask-Karteczka (1999), Water circulation. In: L. Starkel (ed.), Geography of Poland. Natural Environment, Warszawa, 343-373 (in Polish).

Hattermann, F.F., Z.W. Kundzewicz, S. Huang, T. Vetter, F.-W. Gerstengarbe, and P. Werner (2013), Climatological drivers of changes in flood hazard in Germany, Acta Geophys. 61, 2, 463-477, DOI: 10.2478/s11600-012-00704.

Kawachi, T., T. Maruyama, and V.P. Singh (2001), Rainfall entropy for delineation of water resources zones in Japan, J. Hydrol. 246, 1-4, 36-44, DOI: 10.1016/S0022-1694(01)00355-9.

Koutsoyiannis, D. (2005), Uncertainty, entropy, scaling and hydrological stochastics, 1, Marginal distributional properties of hydrological processes and state scaling, Hydrol. Sci. J. 50, 3, 381-404, DOI: 10.1623/hysj.50.3.381. 65031.

Krasovskaia, I. (1995), Quantification of the stability of river flow regimes, Hydrol. Sci. J. 40, 5, 587-598, DOI: 10.1080/02626669509491446.

Krasovskaia, I. (1997), Entropy-based grouping of river flow regimes, J. Hydrol. 202, 1-4, 173-191, DOI: 10.1016/S0022-1694(97)00065-6.

Krstanovic, P.F., and V.P. Singh (1992), Transfer of information in monthly rainfall series of San Jose, California. In: V.P. Singh and M. Fiorentino (eds.), Entropy and Energy Dissipation in Water Resources, Kluwer Academic Publishers, 155-173, DOI: 10.1007/978-94-011-2430-0_8.

Kundzewicz, Z.W., and S. Huang (2010), Seasonal temperature extremes in Potsdam, Acta Geophys. 58, 6, 1115-1133, DOI: 10.2478/s11600-010-0026-5.

Maruyama, T., and T. Kawachi (1998), Evaluation of rainfall characteristics using entropy, J. Rainwater Catchment Syst. 4, 1, 7-10.

Maruyama, T., T. Kawachi, and V.P. Singh (2005), Entropy-based assessment and clustering of potential water resources availability, J. Hydrol. 309, 1-4, 104113, DOI: 10.1016/j.jhydrol.2004.11.020.

Shannon, C.E. (1948), A mathematical theory of communication, Bell. Labs. Tech. J. 27, 3, 379-423, DOI: 10.1002/j.1538-7305.1948.tb01338.x.

Singh, V.P. (1997), The use of entropy in hydrology and water resources, Hydrol. Process. 11, 6, 587-626, DOI: 10.1002/(SICI)1099-1085(199705)11:6< 587::AID-HYP479>3.0.CO;2-P.

Sonuga, J.O. (1972), Principle of maximum entropy in hydrologic frequency analysis, J. Hydrol. 17, 3, 177-191, DOI: 10.1016/0022-1694(72)90003-0. 
Sonuga, J.O. (1976), Entropy principle applied to the rainfall-runoff process, J. Hydrol. 30, 1-2, 81-94, DOI: 10.1016/0022-1694(76)90090-1.

Strupczewski, W.G., K. Kochanek, E. Bogdanowicz, I. Markiewicz, and W. Feluch (2016), Comparison of two nonstationary flood frequency analysis methods within the context of the variable regime in the representative polish rivers, Acta Geophys. 64, 1, 206-236, DOI: 10.1515/acgeo-2015-0070.

Woś, A. (2010), Climate of Poland in the Second Half of the 20th Century, Wyd. Naukowe UAM, Poznań (in Polish).

Wrzesiński, D. (2010), Spatial Differentiation of the Stability of the Flow Regime of European Rivers, Bogucki Wydawnictwo Naukowe, Poznań (in Polish).

Wrzesiński, D. (2013a), Entropy of River Flows in Poland, Studia i Prace z Geografii i Geologii 33, Bogucki Wydawnictwo Naukowe, Poznań, 204 pp. (in Polish).

Wrzesiński, D. (2013b), Uncertainty of flow regime characteristics of rivers in Europe, Quaest. Geograph. 32, 1, 49-59, DOI: 10.2478/quageo-2013-0006.

Wrzesiński, D. (2014), Uncertainty of the flow regime of rivers in Poland, Monografie Komitetu Gospodarki Wodnej PAN 20, 2, 189-201 (in Polish).

Received 14 July 2015

Received in revised form 23 February 2016

Accepted 5 April 2016 